\title{
Sagebien and Zuppinger water wheels for very low head hydropower applications between 0.3 and $1.5 \mathrm{~m}$
}

EMANUELE QUARANTA (IAHR Member), Postdoctoral Fellow, Department of Environment, Land and Infrastructure Engineering, Politecnico di Torino, Torino, Italy

Email: emanuele.quaranta@polito.it /quarantaemanuele@yahoo.it (author for correspondence)

GERALD MÜLLER, Associate Professor, Engineering and the Environment, University of Southampton, Southampton, United Kingdom

Email: g.muller@soton.ac.uk

Running Head: Sagebien and Zuppinger water wheels 


\begin{abstract}
Sagebien and Zuppinger undershot water wheels are hydropower converters for head differences between 0.3-1.5 m. Today, because of the renewed demand for micro hydropower utilisation, these undershot low-head water wheels may offer an attractive solution. In this paper, comparative model tests at approximately 1:10 scale are reported. The Sagebien wheel was extensively tested using 30 instead of the standard 80 blades to create a more cost-effective solution. The efficiency of Sagebien and Zuppinger wheels was determined as a function of flow rate, wheel speed and head difference. The maximum efficiency of both wheels was $84 \%$. The performance of the Sagebien wheel was less affected by the flow rate, with the efficiency slightly decreasing with increasing head difference. The maximum efficiency of the Zuppinger wheel reduces with reducing flow rate and head difference. In particular the Sagebien wheel has interesting environmental advantages.
\end{abstract}

Keywords: Infrasound; physical model tests; Sagebien undershot water wheel; water mill; Zuppinger undershot water wheel

\title{
1 Introduction
}

In rivers, irrigation canals and at old mill sites there is a substantial amount of hydropower with very low head differences between 0.3 and $1.5 \mathrm{~m}$ available. The power mostly ranges from 5 to $100 \mathrm{~kW}$ (ESHA, 2014). Much of this potential is unused, since modern hydropower technology is not cost effective for such very low head/high flow rate situation, e.g. Bozhinova et al. (2013), Müller \& Kauppert (2004). In the mid-19 ${ }^{\text {th }}$ Century, two types of highly efficient water wheels were developed for such conditions, the Sagebien wheel, and the Zuppinger low-head wheel (Reynolds, 2002). Although both wheel types were in widespread application, very little performance data was available. Recent work on the Zuppinger wheel showed efficiencies of up to $85 \%$. No tests have however been reported on the Sagebien wheel, although its specific geometry promises to avoid some of the Zuppinger wheel's shortcomings such as turbulent losses and noise generation at the upstream blade entry. At Southampton University, a series of model tests was conducted with the aims to establish the Sagebien wheel's performance characteristics, and to provide similar and directly comparable data for the Zuppinger wheel.. In the following sections, the wheel types, the tests and the experimental results will be described, and conclusions for their application today will be drawn.

\subsection{The Sagebien wheel}

In 1858 the French engineer Alphonse Sagebien developed a novel type of water wheel for very low head differences. (Fig. 1). The Sagebien wheel had diameters of 7.5 to $10 \mathrm{~m}$, with 70 to 80 blades. The tangential velocity was 0.6 to $0.8 \mathrm{~ms}^{-1}$, and sometimes up to $2 \mathrm{~ms}^{-1}$. The usual rotational speed ranged from 1.5 to $2 \mathrm{rpm}$, and the flow volume per meter width from 1 to $1.2 \mathrm{~m}^{3} \mathrm{~s}^{-1}$. The blades' inclination was set at $40-45^{\circ}$ with respect to the upstream surface of water and leaning forward, to minimize losses 
during blade entry upstream. The blade angle is set so that the blade is parallel with the effective flow velocity vector $w$ given by the combination of the flow velocity vector of the water $v$, and the tangential velocity vector $u$ of the wheel at the entry point ( $w=v-u$, Fig.3a). At higher rotational speeds, this eads to an unfavourable blade exit conditionwhere some water can be lifted upwards,. The wheel's efficiency were estimated as $80 \%$ to $93 \%$, making the Sagebien wheel a very effective machine (Sagebien, 1866; Tresca, 1870). Although several hundred of Sagebien wheels were built in the nineteenth century, the authors are aware of only one experimental investigation. Ely, Kawabata and Cech (2003) conducted tests to assess the potential of Sagebien water wheels for fish upstream migration. They employed a 0.9 $\mathrm{m}$ diameter model wheel with rotational speeds of 1.2 and $2.4 \mathrm{rpm}$, equal to the speed of full scale wheels. They also measured the power conversion efficiency and determined a maximum efficiency of $64 \%$, at $2.4 \mathrm{rpm}$. The low efficiency was probably caused by the very low rotational speed.

\subsection{The Zuppinger wheel}

The Zuppinger undershot water wheel was developed by the Swiss hydraulic engineer Walter Zuppinger and patented in 1853. There were two types of Zuppinger wheels with different inflow configurations, depending on the range of head differences available:

(1) Breastshot wheels for head differences between approximately 1.2 and $2.5 \mathrm{~m}$ with a variable inflow weir to control the upstream water level independently from the flow volume for constant speed operation.

(2) The Zuppinger low-head wheels for head differences from $0.3 \mathrm{~m}$ to $1.5 \mathrm{~m}$ which did not have an inflow weir, Fig. 2.

Only the low-head wheels are considered here. They had diameters of 6 to $7.5 \mathrm{~m}, 32$ to 48 blades, a speed of rotation of 4-4.5 rpm corresponding to tangential velocities of 1.4 to $1.5 \mathrm{~ms}^{-1}$, and flow rates of up to $1.2 \mathrm{~m}^{3} \mathrm{~s}^{-1}$ per meter width. The blades of Zuppinger wheels are shaped in order to minimize power losses at the exit, rather than at the entry. The blades profile at the downstream exit point is normal to the water surface (Fig. 3b). However, at the upstream blade entry point, the blades are almost parallel to the upstream water surface and they slam onto it, generating noise and losses. Their efficiencies were reported as 70 to $75 \%$ (Müller, 1899). Recent tests show efficiencies of up to $85 \%$ for a wheel model of $1.8 \mathrm{~m}$ in diameter and head difference of $0.25 \mathrm{~m}$ (v. Harten, Paudel and Saenger, 2013).

\subsection{Overview}

Sagebien and Zuppinger wheels were developed for the same hydraulic conditions, but several differences exist:

- Sagebien water wheels minimize upstream power losses, whereas Zuppinger wheels minimize downstream power losses; 
- the Sagebien wheel has 70 to 80 blades (Zuppinger: 32 to 48 ). In the literature this is considered as the principal factor for the high costs and limited appeal of the Sagebien wheel, Tresca (1870);

- the reported efficiency of the Sagebien wheel is slightly higher than the efficiency of the Zuppinger wheel;

- the Zuppinger wheel generates a slapping noise with a frequency of 3 to $4 \mathrm{~Hz}$ at blade entry. In or near residential areas, this can be a major drawback.

The similarities can be described as follows:

- both wheel types require a variable speed operation to maintain the upstream water level;

- recent field tests of fish passages on twelve Zuppinger wheels in Germany indicated damage and mortality ratios for fish well below those for turbines or Archimedes Screws, suggesting that these water wheels are fairly eco-friendly (Saenger, 2016).

\section{Experimental setup}

\subsection{Experimental facility and measurement technology}

Physical model tests were conducted in order to quantify the performance of the Sagebien wheel, and to obtain a direct comparison with the Zuppinger wheel. The wheels were designed at a scale of approximately 1:10 with respect to full scale ones, with a diameter of $D=0.600 \mathrm{~m}$ and a width of $b=0.195$ $\mathrm{m}$.

The experiments were conducted in the University of Southampton's Hydraulics Laboratory. The flume used was $12 \mathrm{~m}$ long, $0.30 \mathrm{~m}$ wide and $0.40 \mathrm{~m}$ deep (Fig. 4). The flow rate $\left(Q_{i n}\right)$ ranged from $2.2 \mathrm{l} / \mathrm{s}$ to $7.55 \mathrm{l} / \mathrm{s}$. It was regulated with a pump and a bypass system, and measured using the sharp crested weir at the outlet of the flume, $6.95 \mathrm{~m}$ downstream of the wheel.

The upstream water depth $\left(h_{u}\right)$ was measured $1.69 \mathrm{~m}$ before the axle of the wheel, while the downstream water depth $\left(h_{s}\right)$ was measured $1.50 \mathrm{~m}$ downstream of the wheel, with precision of $\pm 10^{-3} \mathrm{~m}$ using 80 $\mathrm{mm}$ diameter Piezo tubes connected to the bottom of the flume by flexible pipes. Since under the wheel there was a plate $30 \mathrm{~mm}$ thick, the downstream depth over the plate was $h_{d}=h_{s}-30(\mathrm{~mm})$.

\subsection{Water wheel models}

The water wheel models had a diameter of $600 \mathrm{~mm}$, a width of $195 \mathrm{~mm}$ (including two $10 \mathrm{~mm}$ Perspex side disks) and 30 aluminium blades, $150 \mathrm{~mm}$ long, $175 \mathrm{~mm}$ wide and $0.5 \mathrm{~mm}$ thick, Fig. 5. The number of blades in the Sagebien wheel was reduced to 30, to test a geometry with the potential to provide an economic solution. Tests with 80 blades would have been of historic interest only. In addition, recent tests with a Zuppinger wheel have shown that a reduction of blades number from 50 to 25 do not cause any reduction in efficiency (v. Harten et al., 2013). 
Perspex side walls closed off the remaining space in the flume to maintain the water level difference, and to create a $0.562 \mathrm{~m}$ long inflow canal as wide as the inner width of the wheel. A $65 \mathrm{~mm}$ high ramped foam block, made from high density polystyrene, raised the upstream water level and led into a curved shroud below the wheel (Fig. 6). Since the side disks of the wheel were not perfectly straight, small gaps of approximately $4 \mathrm{~mm}$ had to be left on both sides. These gaps were not considered critical since the flow path from upstream to downstream was $300 \mathrm{~mm}$ in length between two plates. A gap of approximately $6 \mathrm{~mm}$ had to be left between the wheel and the shroud to compensate for distortions caused by the applied torque. This was substantially larger than the scaled down gap width of $1.0 \mathrm{~mm}$ (10 mm at full scale) and provided a direct flow path for leakage flow. This aspect will be discussed in section 2.4 .

\subsection{Power take-off: torque and wheel speed measurement and power output estimation}

A Prony friction brake was installed to regulate the wheel rotational speed $(\omega)$, Fig. 6. The Prony Brake used a stationary friction belt around the surface of a $75 \mathrm{~mm}$ friction wheel fastened to the wheel's shaft. A weight $W_{l}$ attached to this belt applies tension to it, creating a friction force $F$ along the profile of the pulley. This caused a braking force on the wheel. When the wheel rotates, the weight $W_{2}$ was transmitted through the belt and measured by a securely fixed digital scale. The friction force $F=W_{1}-W_{2}$ could then be determined. The wheel velocity was measured by using a stopwatch with a precision of $0.01 \mathrm{~s}$. Three different time values for 10 revolutions were recorded for better accuracy and a mean value was taken for the calculations. With a speed of rotation $\omega$ and the friction wheel radius $r$, the power output $P$ can be determined as:

$$
P=T \omega=r F \omega=r\left(W_{1}-W_{2}\right) \omega
$$

\subsection{Leakage estimation}

The large gap below the wheel raised the question of the influence of leakage flow. From observations, it was determined that the gap between the bottom of the wheel blade and the shroud was critical, Fig. 7. In full scale water wheels, the gaps between blades and sides/curved bottom shroud are generally 10 mm wide (e.g. Hydrowatt, 2016). Only a Zuppinger wheel which had been in continuous operation for 89 years, had a gap width of $25 \mathrm{~mm}$ (Neumeyer, Rempp, Ruppert and Schwörer, 1979). With a scale of 1:10, a $10 \mathrm{~mm}$ gap would give a model gap width of $1.0 \mathrm{~mm}$.

The pressure driving the leakage flow below the wheel is generated by the head difference between two blades, see Fig. 6 . Assuming a typical value of $\Delta H=1.0 \mathrm{~m}$ and gap width of $0.01 \mathrm{~m}$ at full scale, five blades in the shroud, and a loss coefficient of 1.0, the flow velocity below the blade would become $1.97 \mathrm{~ms}^{-1}$ (can be estimated from equation (2)), with a Reynolds number of $R=19,700$, i.e. turbulent flow. At 1:10 model scale, this would reduce to $0.62 \mathrm{~ms}^{-1}$ and $\mathrm{R}=620$, i.e. laminar flow, hence a reduced gap flow. Therefore, the gap needs to be larger in order to maintain the turbulent flow regime also through the gaps at the test model. By using a geometrically scaled gap width of $1 \mathrm{~mm}$, this 
would lead to unrealistically low losses (and therefore unrealistically high efficiencies), due to the laminar instead turbulent flow conditions. The existing gap width of $6 \mathrm{~mm}$ gives $R=3,700$, and turbulent flow. As a consequence, flow conditions in model and full scale gaps are turbulent. Leakage flow volume at model scale will however be relatively larger than at full scale. Therefore, model leakage flows need to be estimated to obtain realistic performance values.

For the determination of leakages, the following procedure was chosen:

- the head difference between two buckets $\Delta h$ was determined from the total head difference $\Delta H$ and the number of blades $n$ interacting with the flow. The leakage flow velocity was determined by this head difference. It occurred in the contracted area of the flow just downstream of the blade, of area $C c A_{g, u} \cdot A_{g, u}=a b$ is the gap area, with $a$ the gap vertical width and $b$ the gap horizontal length, as large as the wheel. The coefficient $C c$ is the contraction coefficient taken as 0.61 , being $a / \Delta h<0.6$ in the worst case, and $a / \Delta h$ close to zero at full scale (Citrini, 1987).

- The measured total flow volume $Q_{i n}$ was then reduced by $[(60-10) / 60] Q_{l}$ to simulate the 'real' gap flow through a $10 \mathrm{~mm}$ gap at full scale.

Hence the leakage flow rate was determined by equation (2):

$$
Q_{l}=\operatorname{Cc} A_{g, u}\left[\frac{2 g\left(h_{u}-h_{s}\right)}{n}\right]^{1 / 2}
$$

\subsection{Efficiency}

For the calculation of the power input, flow rate and head difference are required. The head difference $\Delta H$ was determined as the difference between the energy lines upstream and downstream of the wheel:

$$
\Delta H=\left(h_{u}+\frac{v_{u}^{2}}{2 g}\right)-\left(h_{s}+\frac{v_{s}^{2}}{2 g}\right)
$$

where $v_{u}$ is the mean upstream flow velocity, $v_{s}$ is the mean downstream velocity of the flow, $g=9.81$ $\mathrm{ms}^{-2}$ is the acceleration of gravity, and $h_{\mathrm{u}}$ and $h_{\mathrm{s}}$ are the upstream and downstream elevations of the water surface, respectively.

The available hydraulic power input $P_{\text {in }}$ becomes (corrected in order to consider a $10 \mathrm{~mm}$ full scale gap):

$$
P_{i n}=\rho g\left(Q_{i n}-\frac{5}{6} Q_{l}\right) \Delta H
$$

and the efficiency of the wheel $\eta$ is defined as:

$$
\eta=\frac{P}{P_{\text {in }}}
$$


This assumes a full scale gap width of $10 \mathrm{~mm}$ as discussed in the previous section. Therefore, the presented efficiency values will refer to a situation where the equivalent full scale leakages are computed.

\subsection{Experimental conditions and procedure}

The investigated flow rates ranged from $Q_{\text {in }}=2.2$ to $7.55 \mathrm{ls}^{-1}$, wheel velocities between $\omega=5$ to $45 \mathrm{rpm}$, upstream water depths between $h_{u}=130$ to $210 \mathrm{~mm}$ and downstream water depths between $h_{d}=10$ to $80 \mathrm{~mm}$. The flow rate was set using the bypass valve. The downstream water depth was then fixed by the downstream regulating weir. The wheel speed, and the upstream water level depended on the weight $W_{1}$ applied onto the friction brake of the wheel. The maximum flow rate was limited by the condition that $h_{u} \leq 220 \mathrm{~mm}$ (height of the canal's side walls). The highest wheel speed occurred when no braking torque was applied to the wheel: this was the free wheel velocity (45 rpm maximum). With increasing load, the wheel speed reduced. The minimum wheel speed depended on the upstream water level (which increased with reducing wheel speed, but it must be below $h_{u}=220 \mathrm{~mm}$ ), and the proper functioning of the friction brake. The minimum wheel rotational speed was between 5-8 rpm for the Zuppinger, and between 5-10 rpm for the Sagebien wheel.

\section{Results}

\subsection{Power output and efficiency}

The main aim of the tests was to determine the performance characteristics of the Sagebien wheel, and the comparative values for the Zuppinger wheel. Figure 8 shows the power output versus the wheel speed, for three downstream water depths. The power output reduces for both wheels with increasing speed, and increasing downstream water depth. After the determination of the power output, the efficiency was calculated using equation. 6 , and assuming a $10 \mathrm{~mm}$ gap at full scale to analyse the relationship between efficiency and wheel velocity.

Figure 9 shows the efficiency as a function of the flow volume $Q$ normalised with the design flow $Q_{D e s}$, which is the flow rate at maximum efficiency for each downstream water depth. The Sagebien wheel has a near constant efficiency of more than $80 \%$ (with a maximum of $84 \%$ ) for all flow volumes around the design flow, whilst the Zuppinger wheel efficiency has a maximum of $84 \%$, depending on the downstream depth, and reduces for higher and lower flow volumes. Figure 10 shows hill graphs for both wheels, with the optimal rotational speed and efficiency as a function of the downstream water depth $h_{\mathrm{d}}$ and flow rate $Q$. The graphs indicate that for maximum efficiency under variable flow conditions, a variable speed operation with a ratio of maximum to minimum wheel speed $u_{\max } / u_{\min } \approx 2$ is required. Using these hill graphs, the optimal rotational speed and efficiency can be estimated. 
In order to compare the efficiency for varying head differences, the wheel tangential velocity $u$ was normalized by normalizing it to the free fall velocity $v_{\max }$ determined with the energy line difference (Figs. 11 and 12). The underlying assumption is that the ideal wheel without losses would rotate with this velocity, making it the upper reference limit. This non-dimensional velocity allows to compare tests with different head differences. Figures 11 and 12 show maximum efficiencies of $84 \%$ and indicate that there is an optimum velocity ratio of $u^{*}=u / v_{\max }=0.20$ to 0.35 for both wheels. The Sagebien wheel has a slightly narrower band width than the Zuppinger wheel. The efficiency reduces for downstream water depths $h_{d} / D<0.1$.

Tables 1 and 2 show the results for the conditions with the highest efficiency $\eta_{\max }$, which occurs at the optimal rotational speed $\omega_{\text {opt }}$. The optimal wheel speed increases with the flow rate. The maximum efficiency of the Sagebien wheel ranges between 64-84\%, and the Zuppinger's between 51-84\%. The maximum efficiency is a function of the head difference and flow rate, as depicted in Fig.12. The optimal rotational speeds for the Zuppinger wheel are between 6.5 to $15.1 \mathrm{rpm}$ for $2.1<Q<6.1 \mathrm{ls}^{-1}$ while for the Sagebien wheel the optimal speed range is 5.9 to $14 \mathrm{rpm}$ for $2.2<Q<6.31 \mathrm{ss}^{-1}$. Tables 1 and 2 also show the efficiencies calculated with the actual measured flow volume, i.e. including the flow through the $6 \mathrm{~mm}$ gap. Assuming a $60 \mathrm{~mm}$ gap at full scale, this would reduce the maximum efficiency from 84 to $77 \%$.

Tables 1 and 2 also show the filling ratio. The filling ratio is defined as the percentage of the bucket volume filled with water. The volume of water is calculated from the geometry of the wheel itself (blade depth), the flow rate and the rotational speed of the wheel. For the water wheel design, a filling ratio of 0.5 is recommended, Müller (1899). The measurements indicated optimum filling ratios of 53\% to $87 \%$ for the Zuppinger and 58\% to $90 \%$ for the Sagebien wheel, whereby the optimum filling ratio increases with increasing flow volume.

\subsection{Effect of head difference and flow rate}

In the experiments, the head difference changed with the variations in downstream and upstream water levels. Figure 13 shows the effect of head difference on efficiency. The head difference $\Delta H$ was normalized by dividing it by the diameter $D$ of the wheel. The maximum efficiency was constant for $\Delta H / D<0.15$, and then decreased by increasing head difference for the Sagebien wheel. Considering the Zuppinger wheel, the maximum efficiency decreased with the head difference. For optimum efficiency, the ratio of head difference $\Delta H$ and wheel diameter $D$ should be in the range of $0.08 \leq \Delta H / D \leq 0.15$ for the Sagebien, and of $0.08 \leq \Delta H / D \leq 0.12$ for the Zuppinger wheel.

\subsection{Noise generation}

During the upstream entry of the blade, the Zuppinger wheel generated a slapping sound. This was caused by the unfavourable effective angle of entry; at the moment of contact, the blade surface is near parallel with the water surface, creating a slamming condition. The resulting acoustic pulse has a 
frequency of 3 to $5 \mathrm{~Hz}$, well below $20 \mathrm{~Hz}$ which is the lower hearing limit, so that it can be classified as an infrasound signal. Such signals have several unwanted aspects:

(1) they travel further than higher frequency signals;

(2) they can have adverse effects on humans (Tandy and Lawrence, 1998);

(3) in this frequency range, the resonance of enclosed air spaces (rooms, space between building etc.) is possible, which can amplify the sound pressure significantly.

In one case, the operation of a Zuppinger low-head wheel had to be stopped during night time because of complaints of nearby residents (Hydrowatt, 2016). The Sagebien wheel has a geometry optimised for blade entry, and this problem does not exist.

\section{Discussion}

\subsection{Overview}

The purpose of the tests was to determine the performance characteristics of the Sagebien wheel, and to provide a direct comparison with its main competitor, the Zuppinger wheel. This allows e.g. to exclude scale effects. For both wheel types, there are efficiency estimates and design recommendations regarding the tangential wheel speed and the filling ratio (and with it the wheel size) given in the literature. Noise generation has never been mentioned. Maximum efficiencies of $90 \%$ were estimated for the Sagebien, and 70 to $75 \%$ for the Zuppinger wheel. Recent model tests gave efficiencies of up to 85\% for the Zuppinger wheel; the Sagebien wheel however was never investigated in detail. The series of model tests described here provided for the first time reliable information for their performance and design.

\subsection{Performance}

For the Zuppinger wheel, the maximum efficiency of $84 \%$ is in good agreement with results reported in the literature. v. Harten et al. (2013) tested a wheel of $1.8 \mathrm{~m}$ diameter, 25 to 50 blades, with a head difference of $0.25 \mathrm{~m}(\Delta H / D=0.14)$ and a maximum efficiency of $84 \%$ at $7.6 \mathrm{rpm}\left(u / v_{\max }=0.32\right)$ for the design flow. This matches the results shown in Fig. 13b. The normalized velocities for maximum efficiency of $0.2 \leq u / v_{\max } \leq 0.35$, were also found in Quaranta \& Revelli (2016) for a breastshot water wheel equipped with a sluice gate inflow. This range of normalized velocities can be considered an optimal working condition for undershot water wheels.

The $0.9 \mathrm{~m}$ diameter Sagebien wheel investigated in Ely et al. (2003) ran at either 1.2 or $2.4 \mathrm{rpm}$. The maximum efficiency of $64 \%$ was reached with an head difference of $0.11 \mathrm{~m}$, and a speed of 2.4 $\mathrm{rpm}$. This corresponds to a tangential speed of only $0.11 \mathrm{~m} / \mathrm{s}$. The wheel normalized velocity then becomes $u^{*}=0.076$, with $\Delta H / \mathrm{D}=0.12$, which is in good agreement with the results here described, (compare Fig. 11a where efficiencies drop for normalized speed $u^{*<0.15}$ is depicted). The very low 
rotational speed of the wheel tested by Ely et al. (2003) corresponds to speeds of 0.4 to $0.8 \mathrm{rpm}$ at full scale, substantially lower than 1.5 to 2 rpm recommended by Sagebien. Their results are also well below the higher optimum operational range $\left(0.2 \leq u^{*} \leq 0.35\right)$ determined in this study. The results from Ely et al. are therefore interesting, but they did not contribute to a realistic assessment of the Sagebien wheel's performance.

Originally, the large diameter of the Sagebien wheel was necessary in order to accommodate the required flow volumes of 1 to $1.2 \mathrm{~m}^{3} / \mathrm{s}$ per meter width with tangential velocities of only $0.8 \mathrm{~m} / \mathrm{s}$. The tests however showed that the tangential velocities of the Sagebien wheel can be chosen nearly as high as those of the Zuppinger wheel. The optimum filling ratio is not constant, but increases for increasing flow volume and wheel speed. With a maximum value of 0.8 for the design condition, it is substantially higher than the ratio of 0.5 recommended e.g. by Müller (1899).

\subsection{Design recommendations}

The results indicated that the Sagebien wheel can be built with 30 blades instead of 70 or 80 without loss of efficiency, that its diameter can be similar to that of the Zuppinger wheel (6 to $7.5 \mathrm{~m}$ ), whilst a higher tangential speed allows to process an increased volume of water. The low-speed performance of the Sagebien wheel appears to be slightly better than the Zuppinger wheel, and the absence of slamming and slam induced infrasound is a definite operational advantage.

The tests results allow to provide more accurate design recommendations. The maximum design flow for both wheel types should be chosen as 1 to $1.2 \mathrm{~m}^{3} / \mathrm{s}$ per meter width, as recommended in the literature. The maximum tangential velocity can be taken as 1.15 to $1.2 \mathrm{~m} / \mathrm{s}$ at design conditions. The Sagebien wheel can rotate faster than recommended, whilst the tangential velocity of $1.5 \mathrm{~m} / \mathrm{s}$ given for the Zuppinger wheel appears to be too high. Further recommendations:

- the diameter of the Sagebien wheel can be reduced to $6 \div 8 \mathrm{~m}$;

- the ratio of downstream water depth to diameter $\left(h_{d} / D\right)$ should not be less than 0.1 to avoid low efficiencies;

- the ratio of head difference $\Delta H$ to wheel diameter $D$ should vary between $0.08 \leq \Delta H / D \leq 0.15$ (Sagebien wheel), and $0.08 \leq \Delta H / D \leq 0.12$ (Zuppinger wheel);

- the tangential speed ratio of the wheel $u / v_{\max }$ should be in the range of $0.20 \leq u / v_{\max } \leq 0.35$ (Sagebien wheel) and $0.20 \leq u / v_{\max } \leq 0.40$ (Zuppinger wheel), where $v_{\max }=(2 g \Delta H)^{1 / 2}$;

- the filling ratio at design flow condition can be increased to 0.7 to 0.8 .

\section{Conclusions}

A series of tests was conducted on two types of undershot water wheels for head differences of 0.3 to $1.5 \mathrm{~m}$ (Sagebien and Zuppinger wheels) to determine their performance, and to identify the optimal 
working conditions. The Sagebien wheel was tested for the first time, whereby a modified geometry with 30 instead of the traditional 70 to 80 blades was employed to model a cost-effective design.

The following conclusions were drawn:

- Maximum efficiencies for both wheel types reached $84 \%$. The reduced number of blades in the Sagebien wheel did not have any negative effects.

- The recommended maximum design flow volume of $1.2 \mathrm{~m}^{3} / \mathrm{s}$ per meter width was confirmed.

- Tangential speeds for both wheels should not exceed $1.2 \mathrm{~m} / \mathrm{s}$. Previous recommendations underestimated the tangential speed for the Sagebien wheel, and overestimated the speed for the Zuppinger wheel.

- In consequence, the diameter of the Sagebien wheel can be reduced from $8 \div 10$ to $6 \div 8 \mathrm{~m}$.

- The optimum wheel velocity is a function of the head difference. The ratio of design tangential speed and theoretical tangential free wheeling velocity should be between 0.2 and 0.35 (Sagebien wheel).

- The Sagebien wheel's efficiency is nearly independent of the flow volume, whilst efficiencies for the Zuppinger wheel have a well identified maximum at $Q / Q_{D e s}=0.75$, and reduce for lower flow volumes.

Whilst both wheels have excellent ecological characteristics, the Sagebien wheel has the additional environmental advantage that, contrary to the Zuppinger wheel, it does not generate infrasound emissions. The Sagebien wheel appears to have further development potential.

\section{Acknowledgements}

We would like to thank Jean-Pierre Henri AZEMA (Fédération Des Moulins de France FDMF), MariePaule Dupuy (Région Aquitaine-Limousin-Poitou-Charentes - Direction de la Culture - Service du patrimoine), Denoel C. (Condroz Energies Citoyennesscrl) and Patrick H.M. for their support in the pictures selection of existing water wheels. We also thank the technicians Toru Tsuzaki and Karl Scammell for their practical help.

\section{Notation}

$A_{g, u}=$ area of the bottom horizontal gap $\left(\mathrm{m}^{2}\right)$

$a=$ gap width (m)

$b=$ canal width $(\mathrm{m})$

$d=$ height of the downstream weir (m)

$F=$ friction force $(\mathrm{N})$ 
$g=$ acceleration of gravity $\left(\mathrm{ms}^{-2}\right)$

$h_{u}=$ upstream water depth $(\mathrm{m})$

$h_{d}=$ downstream water depth over the base plate of the wheel (m)

$h_{s}=$ downstream water depth $(\mathrm{m})$

$n=$ number of wet blades $(-)$

$P=$ mechanical power output $\left(\mathrm{Nms}^{-1}\right)$

$P_{i n}=$ hydraulic power input $\left(\mathrm{Nms}^{-1}\right)$

$Q=$ actual flow rate through the wheel $\left(\mathrm{m}^{3} \mathrm{~s}^{-1}\right)$

$Q_{D e s}=$ design flow rate $\left(\mathrm{m}^{3} \mathrm{~s}^{-1}\right)$

$Q_{\text {in }}=$ total inflow rate $\left(\mathrm{m}^{3} \mathrm{~s}^{-1}\right)$

$Q_{l}=$ leakages $\left(\mathrm{m}^{3} \mathrm{~s}^{-1}\right)$

$r=$ radius of the pulley $(\mathrm{m})$

$t=$ water head over the weir $(\mathrm{m})$

$T=$ torque $(\mathrm{Nm})$

$u=$ wheel tangential speed $\left(\mathrm{ms}^{-1}\right)$

$v=$ absolute entry stream velocity $\left(\mathrm{ms}^{-1}\right)$

$v_{\max }=$ reference flow velocity $\left(\mathrm{ms}^{-1}\right)$

$v_{u}=$ upstream flow velocity $\left(\mathrm{ms}^{-1}\right)$

$v_{s}=$ downstream flow velocity $\left(\mathrm{ms}^{-1}\right)$

$\boldsymbol{w}=$ relative entry velocity of flow $\left(\mathrm{ms}^{-1}\right)$

$W_{1}=$ applied weight $(\mathrm{kg})$

$W_{2}=$ weight read on the scale $(\mathrm{kg})$

$\Delta h=$ head difference between two buckets (m)

$\Delta H=$ head difference $(\mathrm{m})$

$\eta=$ efficiency $(-)$

$\rho=$ water density $\left(\mathrm{kgm}^{-3}\right)$

$\omega=$ wheel rotational speed $\left(\operatorname{rads}^{-1}\right)$

$\mathrm{R}=$ Reynolds number $(-)$ 


\section{References}

Bozhinova, S, Isliakov, D., Müller, G., Hecht, V., \& Schneider, S. (2013). Hydropower converters with head differences below $2.5 \mathrm{~m}$. Proceedings of the ICE-Energy, 166(3), 107-119.

Citrini, D., \& Noseda, G. (1987). Idraulica [Hydraulics]. Published by Casa Editrice Ambrosiana, Milano (in Italian).

Ely, R., Kawabata, A., \& Cech, J. (2003). The Sagebien project. Davis Hydro, EISG Final report.

ESHA (European Small Hydropower Association). (2014). Small and micro hydropower restoration handbook. National Technical University of Athens, Athens, Greece.

v. Harten M., Paudel S., \& Saenger N. (2013). Nutzung kleiner Fallhöhen: aus Forschung und Entwicklung [Utilisation of smallheaddifferences: research and development]. Proc. Tagung Kleinwasserkraft, Technical University of Stuttgart (in German).

Hydrowatt (2016). Pers. Comm.

Müller, W. (1899). Die eisernen Wasserräder, Teil 2: Die Schaufelräder [The iron water wheels, Part 2: blades water wheels]. Veit \& Comp., Leipzig (in German).

Müller, G., \& Kauppert, K. (2004). Performance characteristics of water wheels. Journal of Hydraulic Research, 42(5), 451-460.

Neumayer, H., Rempp, W., Ruppert, J., \& Schwörer, R. (1979). Untersuchungen am WasserradTriebwerk der Kunstmühle W. Seifried KG, Waldkirch-Br. [Investigation of a water wheel power plant at the flour mill W. Seifried KG, Waldkirch/Breisach], Technical Report, University of Stuttgart, Germany (in German).

Quaranta, E., \& Revelli, R. (2016). Optimization of breastshot water wheels performance using different inflow configurations. Renewable Energy, 97, 243-251.

Reynolds, T. (2002). Stronger than a Hundred Men: A History of the Vertical Water Wheel, Johns Hopkins University Press Baltimore and London.

Sagebien, M. (1866). La Roue Hydraulique Sagebien. Expériences sur la roue hydraulique Sagebien, précédées d'un Exposé du principe de ce nouveau moteur à aubes immergentes et à niveau maintenu dans les aubes, Ed.: Eugène Lacroix, Paris (in French).

Saenger N. (2016). Pers. Comm.

Tandy, V., \& Lawrence, T. R. (1998). The ghost in the machine. Journal-Society for psychical Research, 62, 360-364.

Tresca, M. (1870). Roue de l'établissement hydraulique de Trilbardou, par M. Sagebien. Bulletin de la Société d'encouragement à l'industrie nationale, vol. XVII, 193-205 (in French). 
Table 1 Operational conditions (model test flow rate assuming $10 \mathrm{~mm}$ full scale gap, upstream and downstream water depth, head difference), maximum efficiency including leakage in the full scale model $\left(\eta_{\max }\right)$ and in the model test $\left(\eta_{\text {max,t }}\right)$, optimal rotational speed, filling ratio (f.r.) and power output at maximum efficiency for the Sagebien wheel model

\begin{tabular}{ccccccccc}
\hline$Q\left(\mathrm{ls}^{-1}\right)$ & $h_{u}(\mathrm{~m})$ & $h_{s}(\mathrm{~m})$ & $\Delta H(\mathrm{~m})$ & $\eta_{\max }(\%)$ & $\eta_{\text {max_t }}(\%)$ & $\omega_{\text {opt }}(\mathrm{rpm})$ & f.r. $(-)$ & $P(\mathrm{~W})$ \\
\hline 2.21 & 0.160 & 0.048 & 0.087 & 64 & 55 & 9.1 & 0.43 & 1.21 \\
2.21 & 0.151 & 0.065 & 0.084 & 74 & 64 & 6.5 & 0.60 & 1.35 \\
2.24 & 0.160 & 0.088 & 0.072 & 83 & 72 & 5.9 & 0.67 & 1.30 \\
2.27 & 0.170 & 0.110 & 0.061 & 71 & 63 & 4.6 & 0.87 & 0.97 \\
3.36 & 0.189 & 0.048 & 0.137 & 67 & 56 & 8.0 & 0.74 & 3.01 \\
3.63 & 0.156 & 0.065 & 0.088 & 69 & 63 & 11.1 & 0.58 & 2.17 \\
3.65 & 0.168 & 0.085 & 0.082 & 79 & 72 & 9.5 & 0.68 & 2.33 \\
3.60 & 0.195 & 0.107 & 0.087 & 76 & 69 & 7.0 & 0.90 & 2.36 \\
4.76 & 0.193 & 0.055 & 0.133 & 64 & 63 & 10.5 & 0.80 & 4.00 \\
4.78 & 0.192 & 0.063 & 0.125 & 69 & 63 & 10.7 & 0.79 & 4.03 \\
4.85 & 0.181 & 0.089 & 0.091 & 84 & 77 & 11.9 & 0.72 & 3.59 \\
4.84 & 0.205 & 0.109 & 0.094 & 81 & 75 & 9.7 & 0.88 & 3.63 \\
6.19 & 0.203 & 0.065 & 0.133 & 61 & 56 & 11.8 & 0.93 & 4.90 \\
6.27 & 0.185 & 0.089 & 0.094 & 74 & 69 & 13.9 & 0.79 & 4.23 \\
6.29 & 0.194 & 0.108 & 0.085 & 75 & 71 & 12.7 & 0.87 & 3.90 \\
\hline
\end{tabular}


Table 2 Operational conditions (corrected flow rate assuming $10 \mathrm{~mm}$ full scale gap, upstream and downstream water depth, head difference), maximum efficiency including leakage in the full scale model $\left(\eta_{\max }\right)$, and in the model test $\left(\eta_{\text {max, }}\right)$, optimal rotational speed, filling ratio (f.r.) and power output at maximum efficiency for the Zuppinger wheel model

\begin{tabular}{ccccccccc}
\hline$Q\left(1 \mathrm{~s}^{-1}\right)$ & $h_{u}(\mathrm{~m})$ & $h_{s}(\mathrm{~m})$ & $\Delta H(\mathrm{~m})$ & $\eta_{\max }(\%)$ & $\eta_{\text {max }, \mathrm{t}}(\%)$ & $\omega_{\text {opt }}(\mathrm{rpm})$ & f.r. $(-)$ & $P(\mathrm{~W})$ \\
\hline 2.13 & 0.127 & 0.039 & 0.086 & 52 & 44 & 6.5 & 0.53 & 0.93 \\
2.18 & 0.126 & 0.06 & 0.065 & 57 & 50 & 8.7 & 0.41 & 0.80 \\
3.08 & 0.155 & 0.044 & 0.108 & 54 & 47 & 6.7 & 0.75 & 1.77 \\
3.17 & 0.136 & 0.065 & 0.070 & 65 & 54 & 8.7 & 0.59 & 1.40 \\
3.21 & 0.140 & 0.086 & 0.053 & 78 & 72 & 7.8 & 0.67 & 1.32 \\
3.23 & 0.156 & 0.107 & 0.049 & 81 & 75 & 6.4 & 0.81 & 1.25 \\
4.58 & 0.185 & 0.064 & 0.118 & 61 & 56 & 8.1 & 0.91 & 3.25 \\
4.68 & 0.159 & 0.087 & 0.070 & 75 & 70 & 10.5 & 0.72 & 2.41 \\
4.71 & 0.170 & 0.109 & 0.060 & 84 & 79 & 9.4 & 0.81 & 2.34 \\
6.16 & 0.179 & 0.064 & 0.109 & 50 & 47 & 11.4 & 0.87 & 3.31 \\
5.96 & 0.184 & 0.087 & 0.094 & 64 & 60 & 11.1 & 0.86 & 3.50 \\
6.20 & 0.162 & 0.108 & 0.053 & 72 & 69 & 15.1 & 0.66 & 2.33 \\
7.87 & 0.179 & 0.084 & 0.089 & 58 & 56 & 16.0 & 0.79 & 4.02 \\
7.87 & 0.202 & 0.107 & 0.093 & 62 & 61 & 12.5 & 0.96 & 4.44 \\
\hline
\end{tabular}


(a)

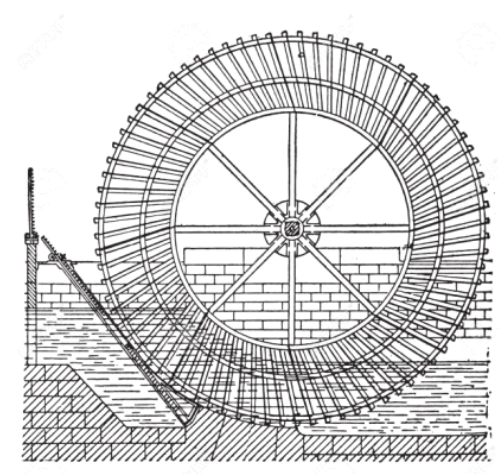

(b)

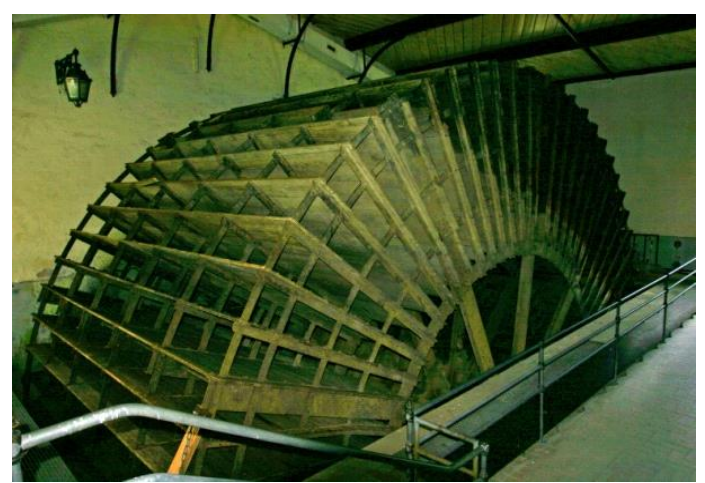

Figure 1 (a) Typical Sagebien water wheel (Industrial encyclopedia E.-O. Lami - 1875). (b) typical Sagebien water wheel (Île de France, Trilbardou, photo of Patrick, H.M, 2007): $D=11 \mathrm{~m}, B=6 \mathrm{~m}, 70$ blades, $P=110 \mathrm{~kW}$

(a)

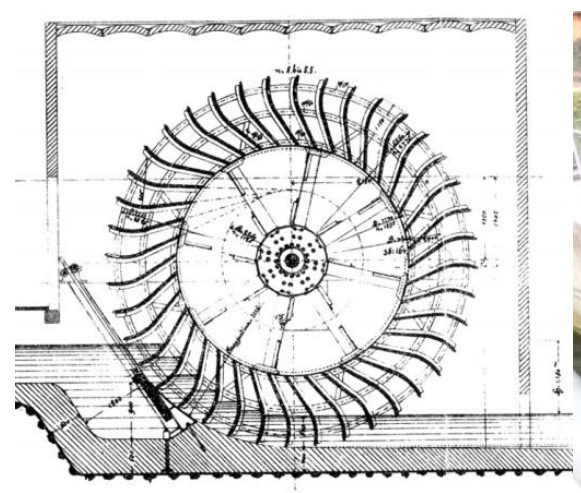

(b)

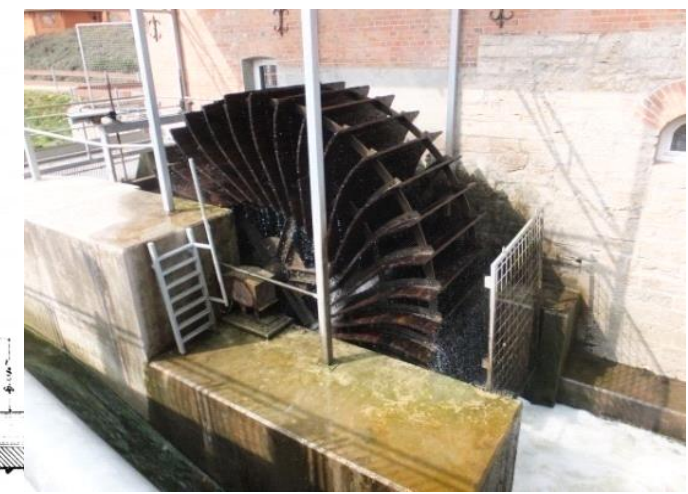

Figure 2 (a) Typical Zuppinger water wheel (Müller, 1899); (b) Existing Zuppinger water wheel (Germany, photo of Müller, 2016): $D=5 \mathrm{~m}, B=2 \mathrm{~m}, H=1.7 \mathrm{~m}, Q=1.8 \mathrm{~m}^{3} \mathrm{~s}^{-1}, P=23 \mathrm{~kW}$, rotational speed $=5 \mathrm{rpm}$ 
(a)

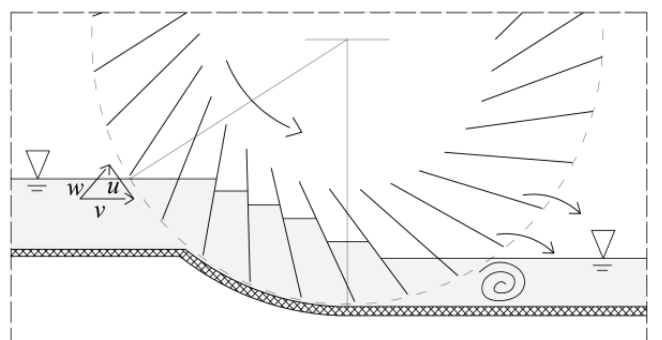

(b)

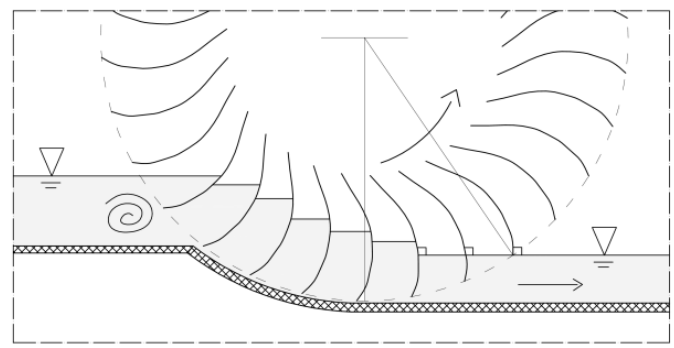

Figure 3 (a) In the Sagebien wheel the blades are shaped in order to reduce the inflow power losses; (b). In the Zuppinger wheel the blades are shaped in order to reduce the outflow power losses

(a)

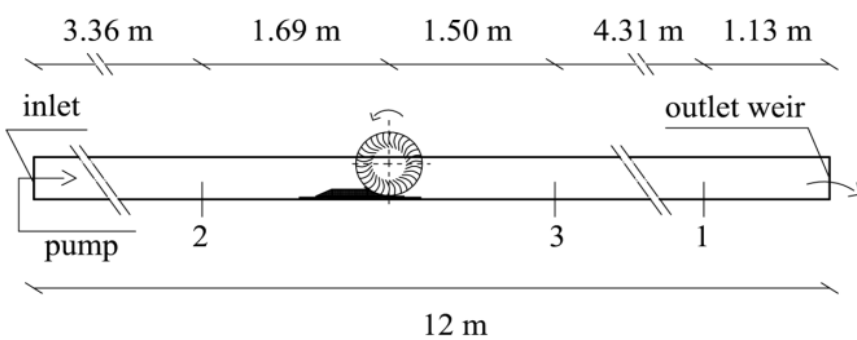

(b)

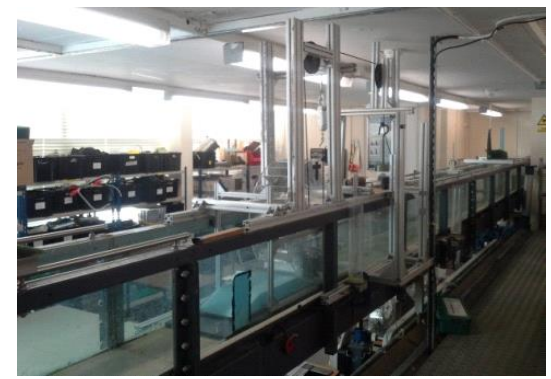

Figure 4 The experimental canal. (a) The water depths were measured in 1 (equation 1), 2 and 3 (upstream and downstream water depth, respectively); (b) picture of the flume

(a)

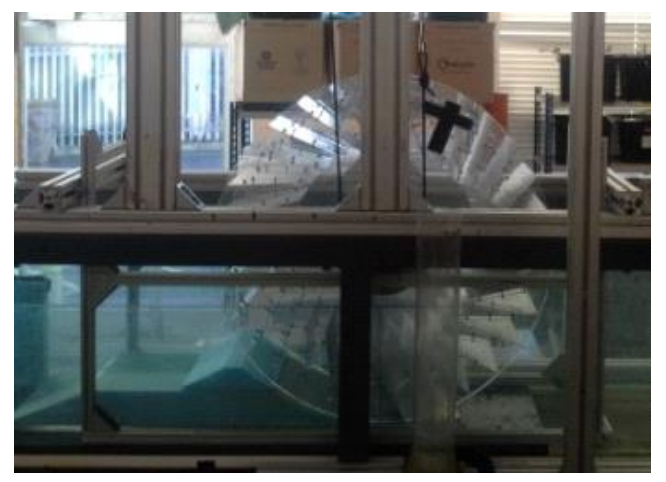

(b)

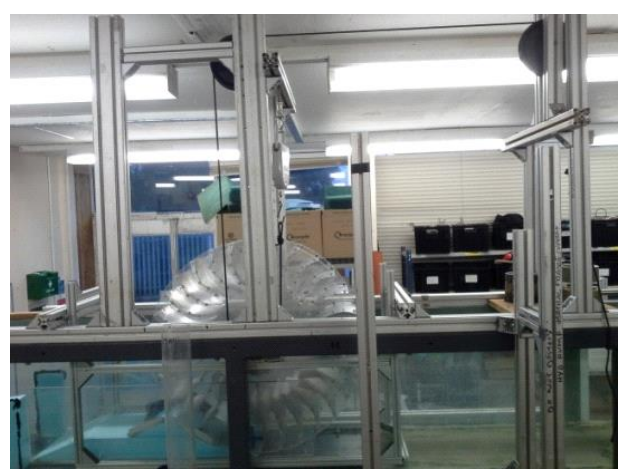

Figure 5 Models: (a) the Sagebien water wheel; (b) the Zuppinger water wheel 

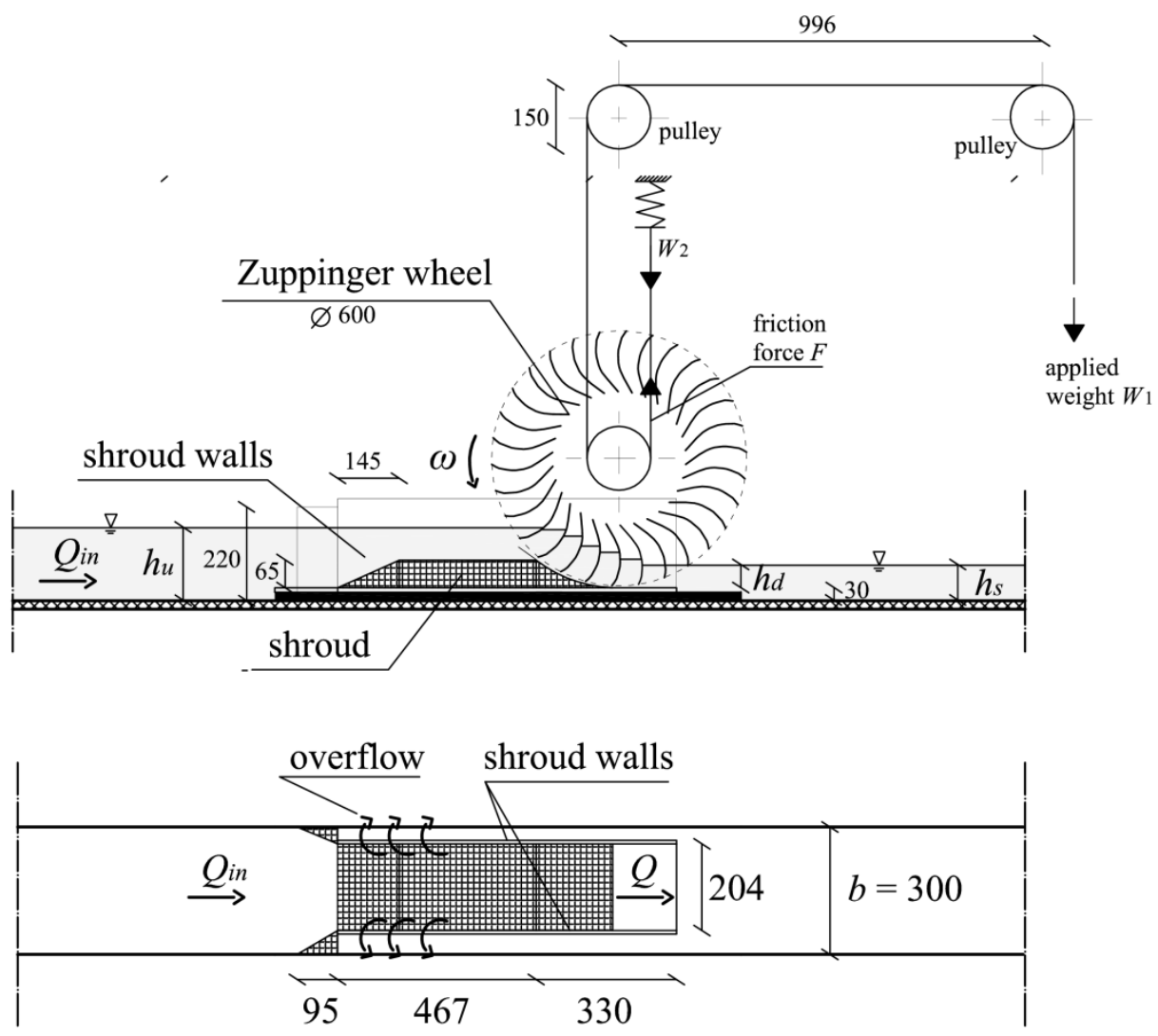

Figure 6 Side and plan view sketch of the canal, Prony brake and Zuppinger wheel (in millimetres). The water depth must be $h_{u}<220 \mathrm{~mm}$ to avoid volumetric losses

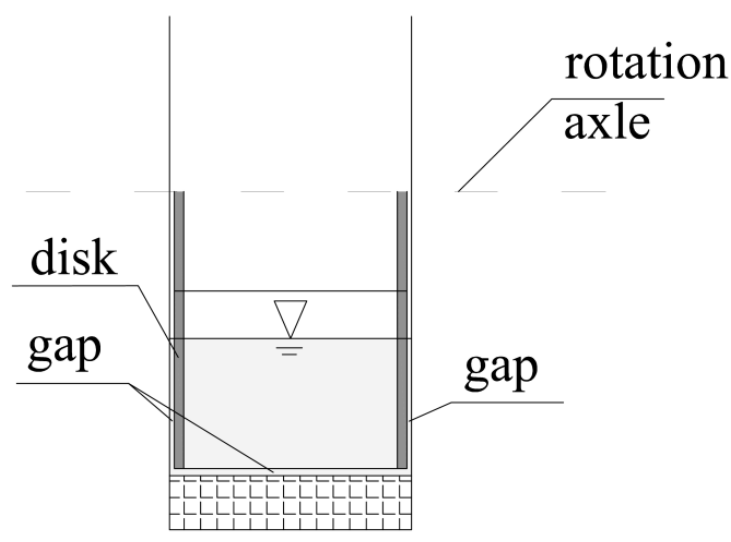

Figure 7 Front elevation of the blades at the inlet 
(a)

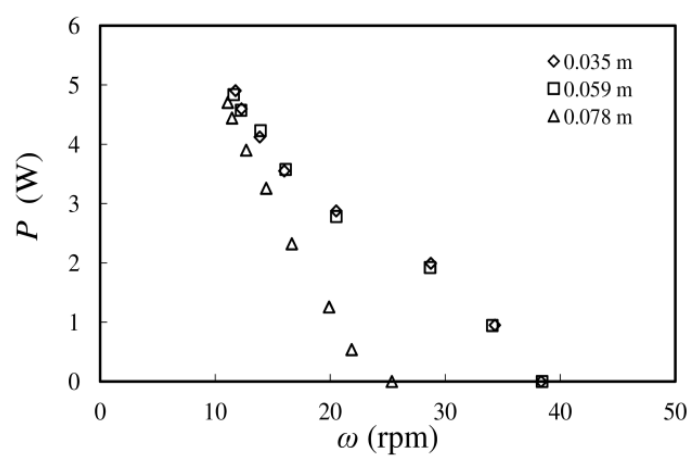

(b)

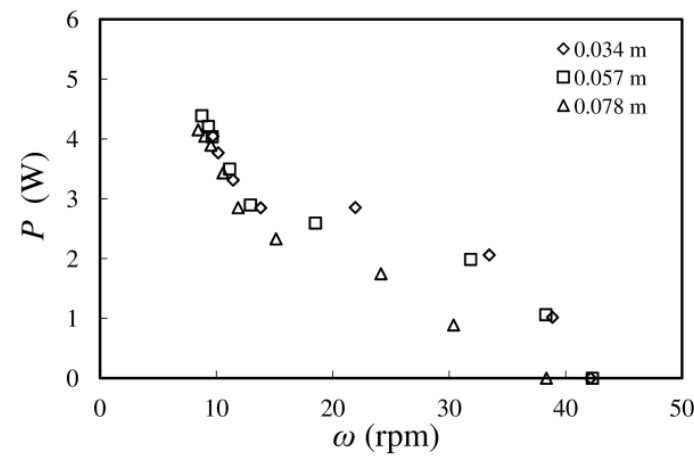

Figure 8 Power output versus the wheel rotational speed at different downstream water depths $h_{d}$ : (a) Sagebien wheel, (b) Zuppinger wheel. Total flow rate of 6.6 1/s.

(a)

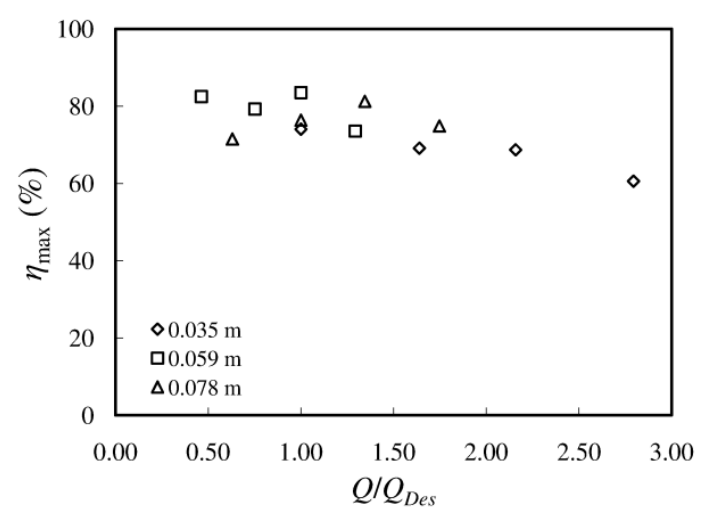

(b)

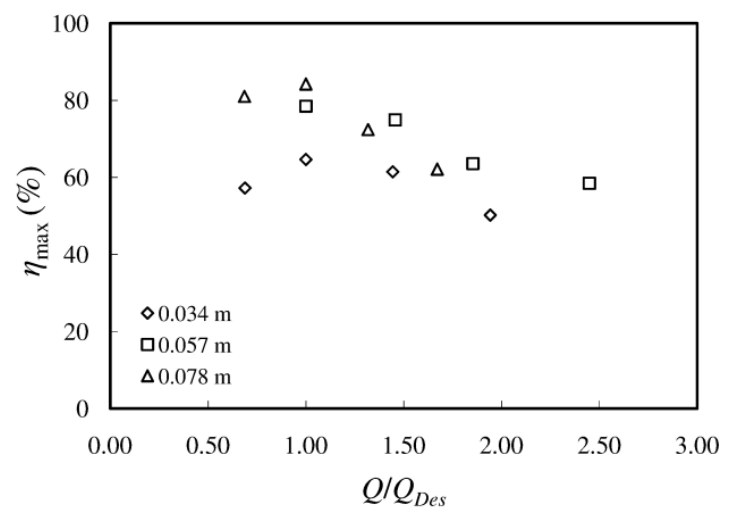

Figure 9 Efficiency and normalised flow volume for different downstream water depths $h_{d}$ : (a) Sagebien wheel, (b) Zuppinger wheel 
(a)

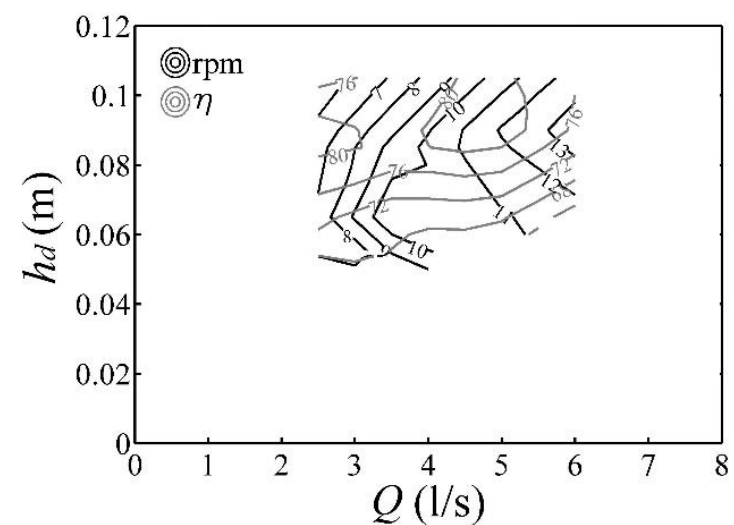

(b)

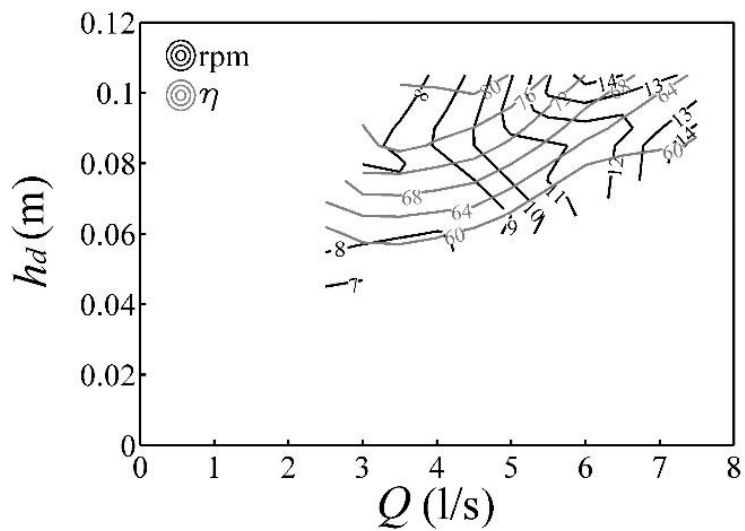

Figure 10 Optimal rotational speeds $(\mathrm{rpm})$ in black and full scale efficiency in gray $(\eta)$ for different downstream water depths $h_{d}$ and flow rates $Q$. (a) Sagebien wheel, (b) Zuppinger wheel

(a)

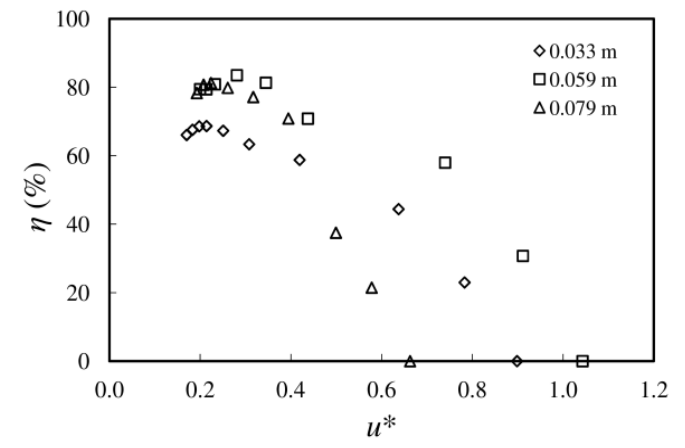

(b)

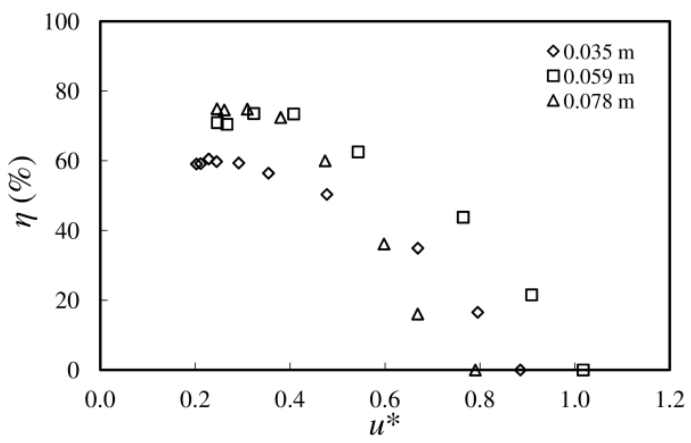

Figure 11: Sagebien wheel, efficiency versus normalized rotational speed for three downstream water depths $h_{d}$, (a) $Q=4.81 \mathrm{l} / \mathrm{s}$, (b) $Q=6.25 \mathrm{l} / \mathrm{s}$ (averaged among the flow rates at three water depths, see Table 1). 
(a)

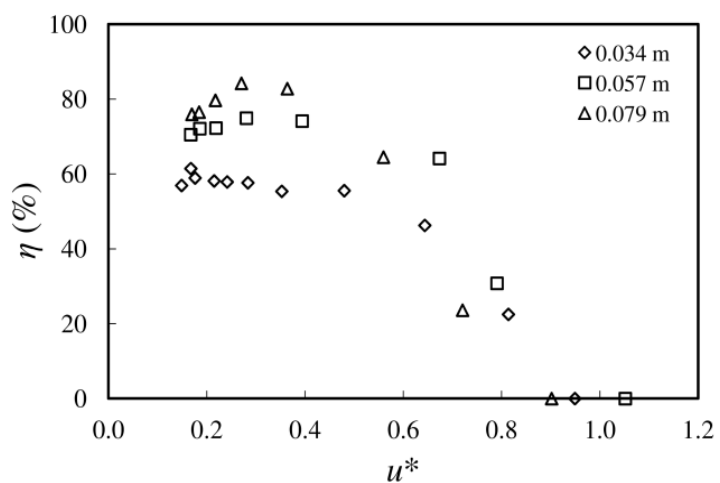

(b)

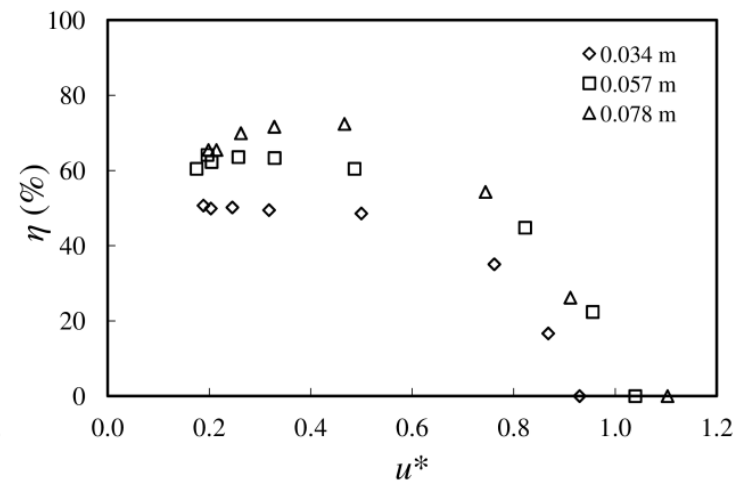

Figure 12: Zuppinger wheel, efficiency versus normalized rotational speed for three downstream water depths $h_{d}$, (a) $Q=4.66$, (b) $Q=6.11$ (averaged among the flow rates at three water depths, see Table 2).

(a)

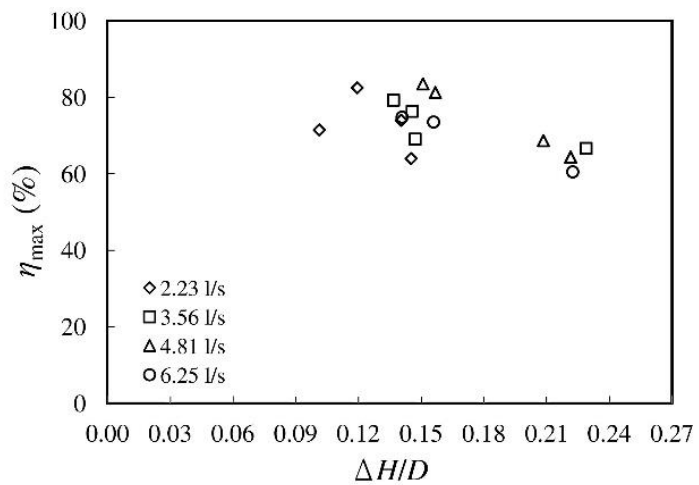

(b)

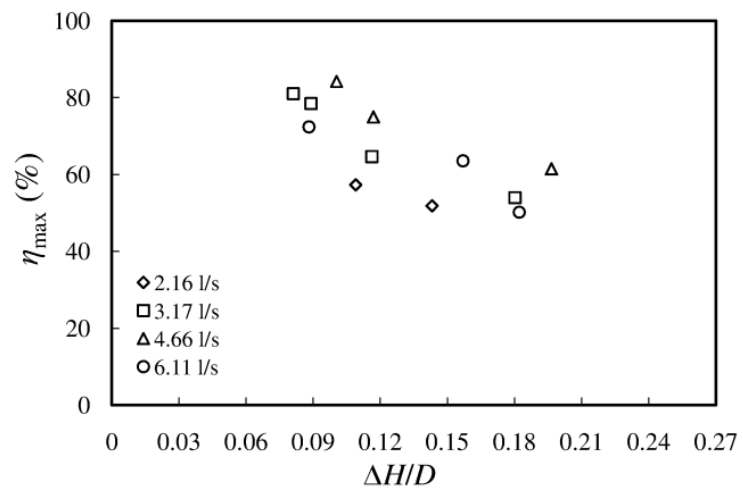

Figure 13 Efficiency versus normalized head difference at different flow rates, for the Sagebien (a) and Zuppinger (b) wheel 